\title{
To: Godsland IF, Jeffs JA, Johnston DG (2004) Loss of beta cell function as fasting glucose increases in the non-diabetic range. Diabetologia 47:1157-1166
}

Received: 18 May 2005 / Accepted: 19 May 2005 / Published online: 17 August 2005

(C) Springer-Verlag 2005

To the Editor:

In the paper by Godsland and colleagues [1], the investigators report a significant decline in beta cell function, which begins within the normal range of fasting plasma glucose (FPG) concentrations. Using the IVGTT in 553 non-diabetic men with an $\mathrm{FPG}<7.0 \mathrm{mmol} / \mathrm{l}$, they observed a marked decline in first-phase insulin secretion, beginning at an FPG well within the normal range, without any change in insulin sensitivity. These results suggest that the decline in insulin secretion is the primary event and is unrelated to changes in insulin sensitivity. A similar observation has been reported in children [2], although most previous studies have demonstrated a decrease in insulin sensitivity in adults with an FPG $>6.1 \mathrm{mmol} / 1(110 \mathrm{mg} / \mathrm{dl})$ $[3,4]$. The defect in first-phase insulin secretion is reminiscent of the decline in insulin secretion observed in normal glucose-tolerant subjects with 2-h plasma glucose concentrations well within the normal range, reported by Gasteldelli and colleagues [5]. Both observations [1, 5] suggest that the current cut-off values that define normal glucose tolerance do not correspond to plasma glucose levels that identify the presence of physiological alterations in insulin secretion in vivo. In their interpretation of the association between the decline in first-phase insulin secretion and the rise in FPG in response to intravenous glucose, Godsland et al. suggest that loss of pancreatic beta cell function in the first phase is, therefore, the critical factor in declining glucose homeostasis in the non-diabetic range of FPG [1]. Although we agree that impaired beta cell function occurs in individuals with FPG concentrations that are considered to be within the normal range [5], we are concerned about the authors' interpretation of their results. The decline in first-phase insulin secretion that ac-

M. A. Abdul-Ghani $(\bowtie) \cdot$ R. A. DeFronzo

Division of diabetes, University of Texas,

Health Science Center,

7703 Floyd Curl Drive,

San Antonio, TX 78229, USA

e-mail: abdulghani@uthscsa.edu

Tel.: +1-210-5676691

Fax: +1-210-5676554 companies the rise in FPG does not necessarily indicate a causal relationship. One could argue that the increase in FPG, secondary to excess hepatic glucose production or insulin resistance in peripheral tissues, is the primary event and that chronic, sustained modest hyperglycaemia leads to impaired insulin secretion, i.e. glucotoxicity. A 'glucotoxic' effect of hyperglycaemia has been demonstrated in vivo, both in humans and animals, and in vitro in cell culture systems [6-8]. In normal rats, small $(0.89 \mathrm{mmol} / \mathrm{l}$ or $16 \mathrm{mg} / \mathrm{dl})$ increments in mean daylong FPG have been shown to completely abolish first-phase insulin secretion [7]. Such an effect in humans could explain the results observed by Godsland et al. [1]. Moreover, in animal studies, correction of chronic hyperglycaemia with phlorizin restores first-phase insulin secretion, indicating that the reduction in first-phase insulin secretion is the result of chronic hyperglycaemia rather than the cause in this animal model [6]. Although a similar study in man is needed to establish that hyperglycaemia is the primary disturbance and leads to impaired insulin secretion, indirect evidence supports this scenario. First, correction of hyperglycaemia improves insulin secretion in type 2 diabetic subjects [9]. Second, hemipancreatectomy in healthy human donors results in the loss of as much as two-thirds of first-phase insulin secretion following surgery, but does not lead to an increase in FPG [10]. This latter observation strongly argues against the interpretation of Godsland and colleagues [1]. We believe that the observation that first-phase insulin secretion starts to decline as FPG rises above $5 \mathrm{mmol} / 1$ is very important and is consistent with our previous observations [5]. However, what is cause and what is effect remains to be determined.

Two other comments about the study of Godsland et al. [1] should be noted. First, the authors have no information about insulin secretion during glucose administration through the normal route, i.e. via the gastrointestinal tract. First-phase insulin secretion is an 'artifact' of acute intravenous glucose administration and there is no identifiable first-phase insulin secretion following glucose ingestion. Nonetheless, several previous studies have demonstrated that loss of first-phase insulin secretion is a predictor of 
the eventual development of type 2 diabetes. Second, it is very strange that the investigators were not able to observe any evidence of insulin resistance in individuals with FPG levels between 6.1 and $7.0 \mathrm{mmol} / 1$ (110 and $126 \mathrm{mg} / \mathrm{dl}$ ). Many of these individuals would be expected to have IGT or even overt diabetes mellitus, both of which are characterised by moderate to severe insulin resistance $[4,5]$. This raises serious concerns that the IVGTT and sampling programme employed by Godsland et al. [1] were not sensitive enough to detect the impairment in insulin action that is characteristic of individuals with IGT or diabetes.

\section{References}

1. Godsland IF, Jeffs JA, Johnston DG (2004) Loss of beta cell function as fasting glucose increases in the non-diabetic range. Diabetologia 47:1157-1166

2. Yeckel CW, Taksali SE, Dziura J et al (2005) The normal glucose tolerance continuum in obese youth: evidence for impairment in beta-cell function independent of insulin resistance. J Clin Endocrinol Metab 90:747-754
3. Reaven GM, Hollenbeck CB, Chen YD (1989) Relationship between glucose tolerance, insulin secretion, and insulin action in obese individuals with varying degrees of glucose tolerance. Diabetologia 32:52-55

4. Weyer C, Bogardus C, Pratley RE (1999) Metabolic characteristics of individuals with impaired fasting glucose and/or impaired glucose tolerance. Diabetes 48:2197-2203

5. Gastaldelli A, Ferrannini E, Miyazaki Y, Matsuda M, DeFronzo RA (2004) Beta-cell dysfunction and glucose intolerance: results from the San Antonio metabolism (SAM) study. Diabetologia 47:31-39

6. Rossetti L, Shulman GI, Zawalich W, DeFronzo RA (1987) Effect of chronic hyperglycemia on in vivo insulin secretion in partially pancreatectomized rats. J Clin Invest 80:1037-1044

7. Leahy JL, Bonner-Weir S, Weir GC (1988) Minimal chronic hyperglycemia is a determinant of impaired insulin secretion after an incomplete pancreatectomy. J Clin Invest 81:1407-1414

8. Olson LK, Redmon JB, Towle HC, Robertson RP (1993) Chronic exposure of HIT cells to high glucose concentrations paradoxically decreases insulin gene transcription and alters binding of insulin gene regulatory protein. J Clin Invest 92:514 519

9. Garvey WT, Olefsky JM, Griffin J, Hamman RF, Kolterman OG (1985) The effect of insulin treatment on insulin secretion and insulin action in type 2 diabetes mellitus. Diabetes 34:222-234

10. Seaquist ER, Robertson RP (1992) Effects of hemipancreatectomy on pancreatic alpha and beta cell function in healthy human donors. J Clin Invest 89:1761-1766 